\title{
Measuring and modelling the dispersal of Coccinella septempunctata (Coleoptera: Coccinellidae) in alfalfa fields
}

\author{
WOPKE VAN DER WERF ${ }^{1}$, EDWARD W. EVANS ${ }^{2}$ and JAMES POWELL ${ }^{3}$ \\ ${ }^{1}$ Wageningen University, Department of Plant Sciences, Laboratory of Theoretical Production Ecology, P.O. Box 430, 6700 AK \\ Wageningen, The Netherlands; e-mail: Wopke.vanderWerf@cwe.dpw.wau.nl \\ ${ }^{2}$ Utah State University, Department of Biology, Logan UT 84322-5305, USA \\ ${ }^{3}$ Utah State University, Department of Mathematics \& Statistics, Logan UT 84322-3900, USA
}

Key words. Biological control, Coccinella septempunctata, sevenspotted lady beetle, Coccinellidae, dispersal, immigration, landscape, mark-recapture, modelling, space, Utah, alfalfa, sugar-spraying, volatiles

\begin{abstract}
Dispersal of the sevenspotted lady beetle, Coccinella septempunctata, was measured in a series of mark-release-recapture experiments in Utah alfalfa. In three experiments, samples were taken in a radial pattern around the release point. Released beetles for the most part left the $0.36 \mathrm{ha}$ ( $68 \mathrm{~m}$ diameter) sample area within 24 hours, and their average residence time in the sample area was calculated as 12,6 and $1.6 \mathrm{~h}$ in the three experiments, respectively. The spatial distribution of beetles around the point of release could be described with normal distributions whose variance increased linearly in time with $3.8,1.1$ and $0.34 \mathrm{~m}^{2}$ per hour. In three additional field experiments the departure of marked beetles was compared between sugar-sprayed plots and control plots. Residence time was $20-30 \%$ longer in sugar-sprayed plots than in control plots, with mean residences of 5.3,3.6, and $2.9 \mathrm{~h}$ in the sugar-sprayed plots in the three experiments, respectively, and means of 4.4, 2.7, and $2.4 \mathrm{~h}$ in the control plots. The density of unmarked beetles rose by a factor of 10-20 in the sugar sprayed plots during the first 4 to 6 hours following early morning spraying of sugar. This rapid and substantial increase in density cannot be explained by the slightly longer residence time in sugar-sprayed plots. We hypothesize that the aggregation in sugar-sprayed plots is mostly due to greatly increased immigration into those plots, in response to volatiles produced by the plant-pest-predator assembly.
\end{abstract}

\section{INTRODUCTION}

Biological control of field crop pests by naturally occurring enemies such as predators may be affected profoundly by the amount of enemy resource habitat in agricultural landscapes and by the spatial design of the landscape (Stern et al., 1964; van Emden, 1965; Landis \& Haas, 1992; Marino \& Landis, 1996; Bommarco, 1998; Elliot et al., 1999). The closer resource habitats are to the field crops where natural enemy impact is desired, the more likely it is that the enemies will be timely and effective (van der Werf, 1995; Landis \& van der Werf, 1997; Tscharntke \& Kruess, 1999). The question as to how close is close enough can only be answered if we can assess the dispersal behaviour of natural enemies in diverse landscapes and build spatially explicit models to integrate the available information (Brewster \& Allen, 1997; Brewster et al., 1997; Logan et al., 1997; Corbett, 1998). Knowledge on dispersal is hard to get because it requires spatially explicit studies at the field scale and beyond.

Lady beetles are a well-known and abundant group of aphid predators, and aphids in turn are an important group of pests in field crops. Lady beetles are very mobile. Frazer (1988), for example, suggested that in the order of $50 \%$ of the resident population of lady beetles leave a field each day and are replaced by beetles from outside. Precise estimates of rates of departure and replenishment are scarce in the literature, however (Hodek \& Honěk, 1996). At the within-field scale, studies of lady beetle dispersal have mostly focused on dispersal by walking
(Kareiva, 1987; Kareiva \& Odell, 1987; Xia, 1997). Only a few studies have come to our attention that try to include flight in the analysis of the process of redistribution of lady beetles within and between fields (Davidson, 1924; Kieckhefer \& Olsen, 1974; Ives, 1981). Lady beetles are quite apt to fly, especially under sunny and warm conditions, and short flights provide a mechanism for quick redistribution at the scale of meters and beyond. Flight is the process which most determines their distribution over fields and regions and is hence of large agricultural importance. Too little is known about the impact of flight on distributions in fields to generalize.

Use of sugar sprays offers one experimental means of studying lady beetle dispersal involving flight, as researchers have demonstrated repeatedly the rapid aggregation of these predators in sugar-treated plots (Schiefelbein \& Chiang, 1966; Hagen, 1986; Evans \& Swallow, 1993). Evans \& Richards (1997), for example, found that the spraying of plots or edges in an alfalfa crop with sugar solution rapidly affected the distribution of lady beetles throughout the field. The assumed mechanism by which sugar exerts this effect on the distribution of the beetles is through a lengthening of the residence time in sugar-sprayed areas (Ewert \& Chiang, 1966). This explanation for ladybeetle aggregation in sugar-treated areas is plausible because sugar itself can be used as a food resource, and because the presence of sugar on leaves may point to the presence of aphids, which constitute an essential food resource for ladybeetles. Aphids excrete a sugary waste substance, honeydew. Carter \& Dixon 
(1984) demonstrated that the presence of aphid honeydew increases local residence times of the larvae of Coccinella septempunctata L. (Coleoptera, Coccinellidae).

Studies such as those of Evans \& Richards (1997) show that lady beetle distributions can be manipulated by the administration of sugar sprays to strips or bands of crop or marginal vegetation, but they do not elucidate how the redistribution process works. To find out more about the dynamics of the redistribution process, we designed field experiments in which the dispersal of marked and released lady beetles was followed over space and time.

\section{MATERIAL AND METHODS}

All studies were done during July 1999 in alfalfa fields on the Animal Science Farm of Utah State University, $10 \mathrm{~km}$ southwest of Logan, Utah, USA. Although several ladybeetle species occur in Utah alfalfa, we marked and released only adults of $C$. septempunctata, as this introduced species now accounts for the vast majority of individuals of Coccinellidae occurring in alfalfa fields in northern Utah (Evans, 2000). Adults of C. septempunctata were collected for marking/release from sites where they were most abundant. For the first four field experiments, beetles were collected from a field of barley (Hordeum vulgare) that was heavily infested with aphids. Beetles for the final two field experiments were collected in alfalfa, to rule out the possibility that the observed behaviour in the first four experiments was due to an imposed change of host plant. Lady beetles were marked with paint markers (Decocolor Opaque Paintmarker, Uchida of America Corporation, Barcode 2861702101), except in the first experiment, in which black markers (Sanford Sharpie finepoint permanent marker) were used. Paint was administered after the beetles had been immobilised with $\mathrm{CO}_{2}$. Between capture and marking, and between marking and release, the beetles were kept in ventilated containers or Petri dishes at $9^{\circ} \mathrm{C}$. All releases were made in the early morning, at sunrise or shortly after, because this is the coolest part of the day, which was expected to minimize disturbance-induced dispersal immediately following release.

In all, we conducted six field experiments. Each was conducted in alfalfa grown for hay. During each experiment, a set of sweep samples was taken to determine the density of aphid prey (pea aphids, Acyrthosiphon pisum [Harris]; Aphididae) that were present in the alfalfa.

\section{Dispersal in space: "wagon wheel" experiments}

Three experiments (numbered 1, 2, and 6 to reflect the chronological order in which they were conducted) were designed to measure dispersal of lady beetles over space in time. A circular release area and surrounding 72 sampling stations (Fig. 1) were laid out in the form of a wagon wheel in the middle of a $200 \times 200 \mathrm{~m}$ alfalfa field. The release area was $8 \mathrm{~m}$ in diameter, and sampling stations were located at $0,5,10,15$, 20 , and $25 \mathrm{~m}$ from the edge of the release area. Sampling stations were arranged on 12 transects radiating out from the release area at $30^{\circ}$ angles. For the first, second, and sixth experiment, respectively, 1300,1548 , and 1434 C. septempunctata adults were marked and released at a single time.

Sweep samples were taken at sampling stations at intervals of several hours on the day of release (Day 1). A final sample was taken in the afternoon of Day 2 in the first and second experiments. At each sampling station on each occasion, five $180^{\circ}$ sweeps were taken with a $39 \mathrm{~cm}$ diameter sweepnet. A step of 1 $\mathrm{m}$ was taken between subsequent sweeps. Thus, the first set of sweeps covered distances from the edge of the release area of 0 to $5 \mathrm{~m}$, and so forth. Data are presented as the mean (number of

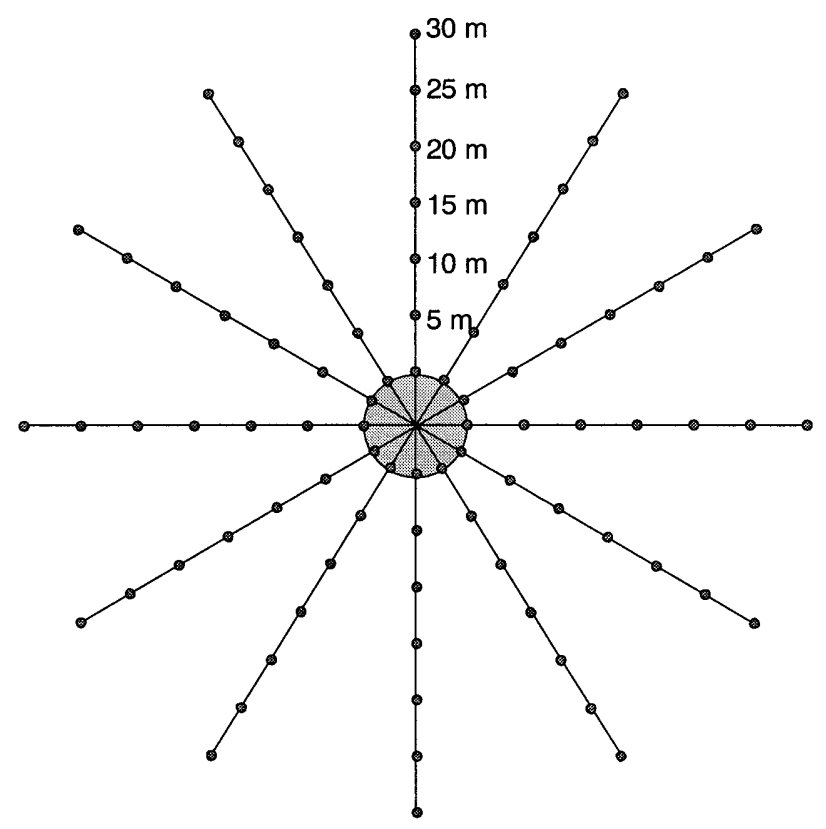

Fig. 1: Sampling design for measuring dispersal within the field.

marked beetles) \pm standard error of the mean (SEM) of the full five sweep samples for each of the six distances $(n=12)$, plus the density in the release area itself.

In the analysis of these data, we developed analytical solutions of the dispersal-departure model:

$$
P_{t}=D \nabla^{2} P-\lambda P
$$

where $P_{t}-$ is the rate of change of population density $P$ at location $(x, y)\left(\# \mathrm{~m}^{-2} \mathrm{~h}^{-1}\right), D-$ is the diffusion coefficient describing lady beetle dispersal within the field $\left(\mathrm{m}^{2} \mathrm{~h}^{-1}\right), \nabla^{2} P=$ $\partial^{2} P / \partial x^{2}+\partial^{2} P / \partial y^{2}$ is the square gradient of population density in two-dimensional space $\left(\# \mathrm{~m}^{-2} \mathrm{~m}^{-2}\right)$,

$\lambda$ is the relative departure rate $\left(\mathrm{h}^{-1}\right)$, i.e., the proportion of beetles which take flight and leave the sampling area per unit time, or the probability per hour that a resident beetle would leave, and $P$ is the density of the ladybeetles at a location $(x, y)\left(\# \mathrm{~m}^{-2}\right)$.

If the release had been a point release, and the samples had been taken at points $(x, y)$, the fundamental solution to equation 1 would be:

$$
F(x, y, t)=\frac{1}{4 \pi D t} \exp \left[-\frac{x^{2}+y^{2}}{4 D t}-\lambda t\right]
$$

In actuality beetles were released at approximately uniform density within a circle of radius $4 \mathrm{~m}$, and the expected density from this release is

$$
P(x, y, t)=2 \pi \iint P_{0} \cdot F(x-u, y-u, t) d u d v
$$

where $P_{0}-$ is the uniform release density (see Logan, 1997). In the fitting process, appropriate corrections were included for the practice of sampling radially extending transects of $5 \mathrm{~m}$ length at each sampling station, and for the size of the release area (full details are available on request). The purpose of fitting is to obtain values for the biologically relevant parameters $D$ and $\lambda$. The diffusion coefficient $D$ characterises the speed of the dispersal process within the sampling area, while the departure rate $\lambda$ characterises the proportion of the beetles that leave the sampling area per unit time. The reciprocal of this rate is the average time that individual beetles spend in the sampling area. 


\section{Effect of sugar sprays on residence time}

Another set of three experiments $(3,4$, and 5) was designed to quantify the departure process more precisely, and to contrast lady beetle departure in sugar-sprayed and control plots. Six sugar-sprayed and six control plots were included in each experiment. Each plot measured $5 \times 10 \mathrm{~m}$, and lady beetles were released in a central area of $3 \times 8 \mathrm{~m}$ within the plot. Sugarsprayed plots received approximately 1.251 of sucrose solution ( $150 \mathrm{~g}$ per 1 of water) applied as a fine mist to the foliage (e.g., Evans \& Richards, 1997). Sugar was sprayed soon after sunrise, and beetles were released immediately afterwards. In the third, fourth, and fifth experiment, respectively, 1678, 1200, and 1380 adults of $C$. septempunctata were marked and released (totals are for all twelve plots combined).

Beetle densities in the plots were estimated by repeated sweepnet sampling. The sampler walked on the long centre line through the plots, taking 8 sweeps in the net area. Samples were subsequently taken at 1-2 hour intervals during the first day and at 1-2 day intervals thereafter. In two of the three experiments (4 and 5), a first sweep sample was taken prior to sugar spraying. Data are presented as average number of beetles (marked or unmarked C. septempunctata adults) per 8 sweeps \pm SEM at each time.

Results were analysed by fitting:

\section{$P=P_{0} \exp [-\lambda t]$}

where $P_{0}-$ is the initial number of ladybeetles (as measured in the first sweepnet sample after release). The other variables and parameters are the same as defined above.

\section{RESULTS}

\section{Lady beetle behaviour; checks on disturbance effects}

During the field experiments, observations were made on the behaviour of the marked beetles, in comparison to that of naturally occurring unmarked beetles. Following release, most beetles walked down the alfalfa stems, seeking refuge after the disturbance caused by release. Within minutes, however, most of the beetles returned to the tops of the alfalfa stems (where many unmarked beetles occurred naturally) to stay there for the next hour or so. At sunrise (the time of release), these stem tops provide the preferred site to warm up after the coolness of the night. After warming up, both experimental and naturally occurring beetles would start foraging by exploring the upper part of the alfalfa stems and leaves. Later in the morning, with the rise in air temperature, flight would become more frequent, both in marked and unmarked beetles. At this time and temperature, both marked and unmarked lady beetles crawling out of the sweepnet were likely to fly away, unless they were promptly put back into the crop canopy, which is what we did. Our direct observations indicate that the arousal, created by the sampling, was thus effectively dissipated. We did not detect any difference in tendency to fly between marked and unmarked beetles. No differences in any of the mentioned behaviours were thus noticed between marked and unmarked C. septempunctata in any of our observations.

\section{Dispersal in space}

Measurements of lady beetle dispersal reveal a spatial bell-shaped distribution around the point of release for each of the three experiments (Fig. 2). In each case, the

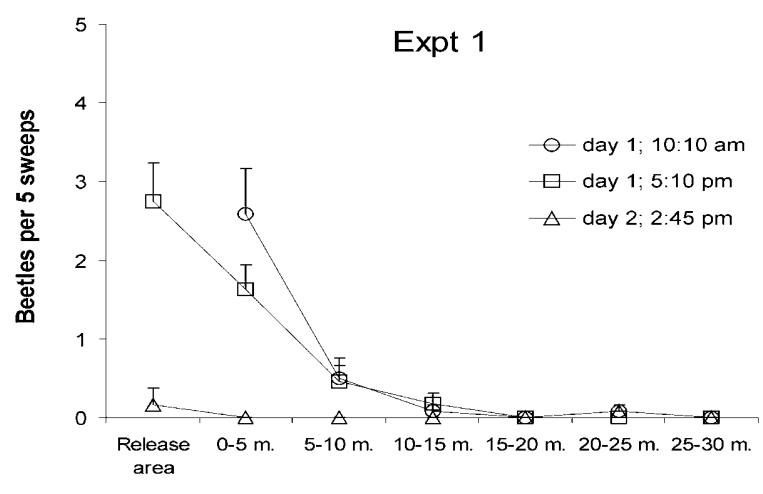

60

Expt 2
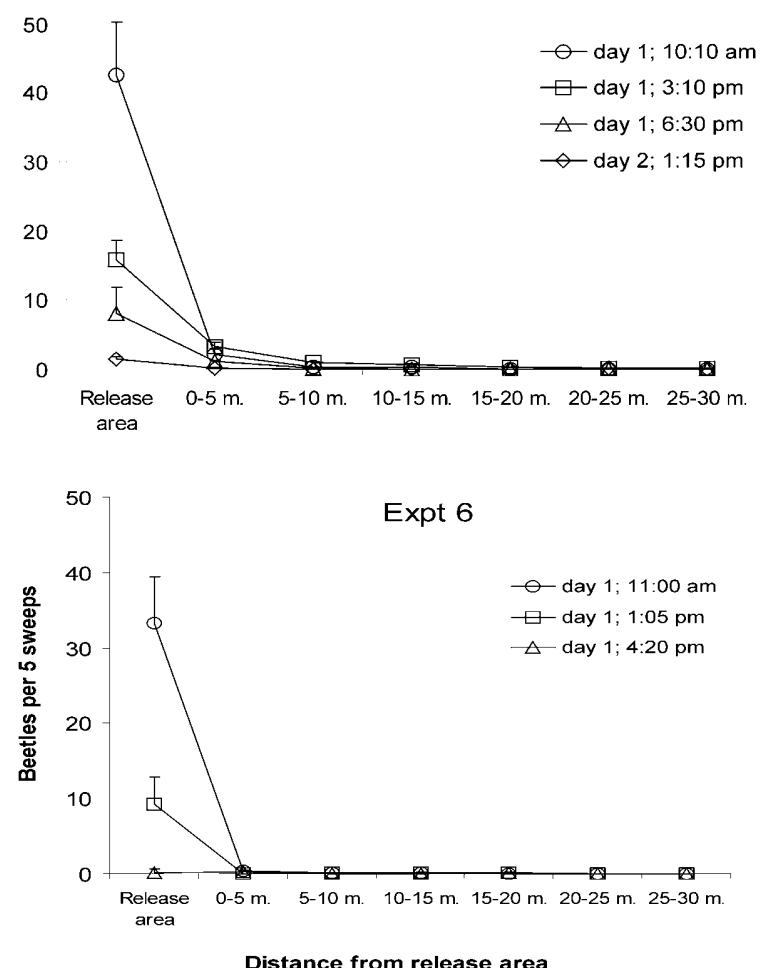

5

Expt 2

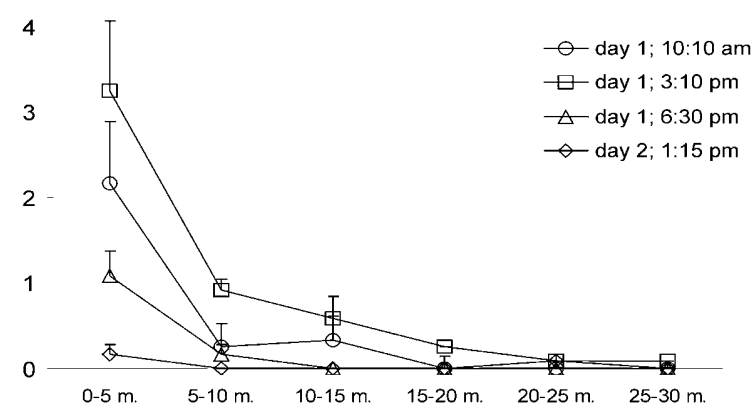

Distance from release area

Fig. 2: Density (expressed as lady beetles per 5 sweeps) of marked and released Coccinella septempunctata in the release area and at six distances from the release area in the course of time in three field experiments in alfalfa. Results for Expt 2 are given with and without data for release area to show clearly the densities within and outside the release area, which differ an order of magnitude. 

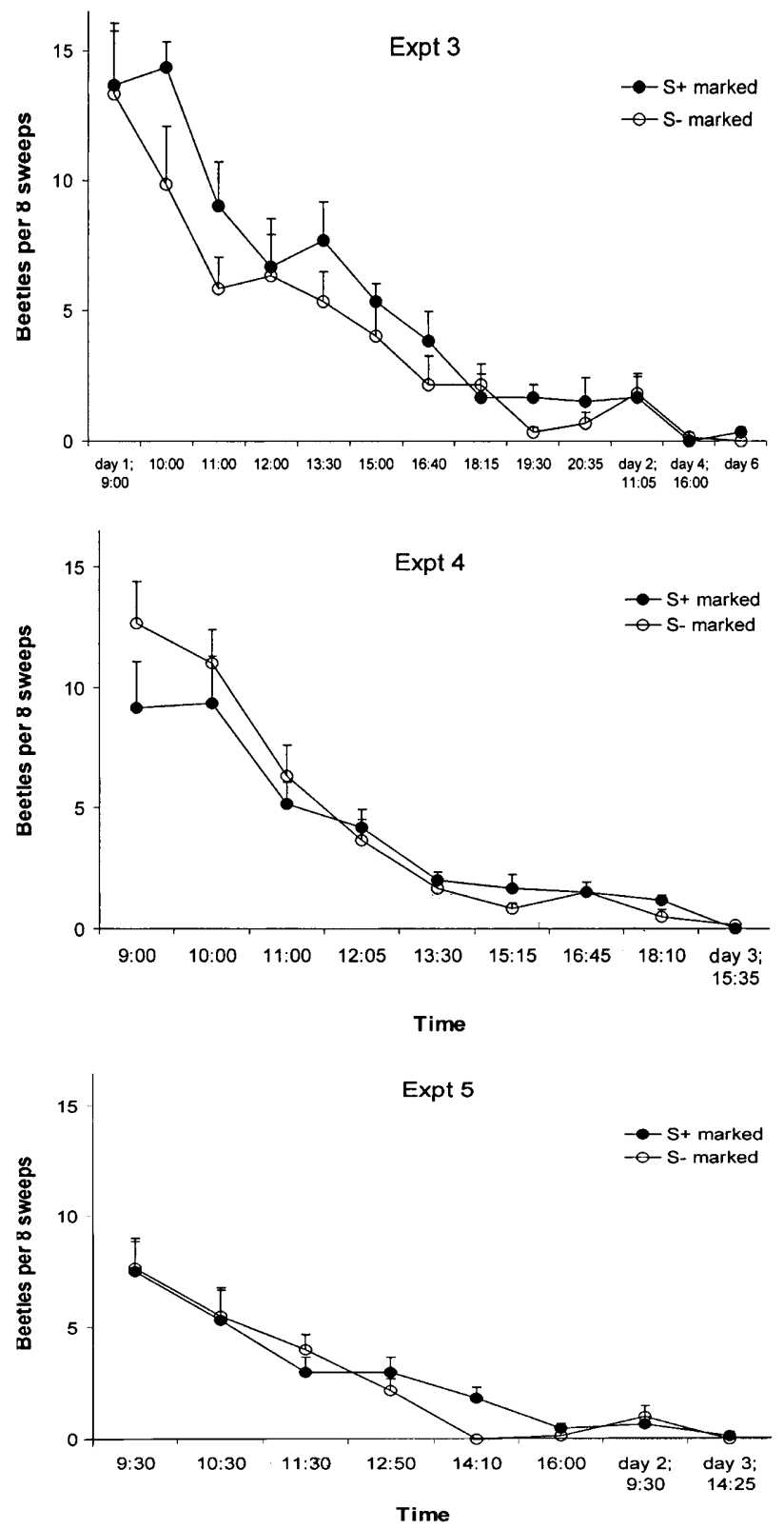

Fig. 3: Density of marked and released Coccinella septempunctata (expressed as lady beetles per 8 sweeps) in sugar sprayed (S+) and control (S-) alfalfa field plots in the course of time after release, in three field experiments in alfalfa.

spatial distribution extended in space as time progressed, and the number of beetles that were recaptured in the sample area declined rapidly. The rate of spatial extension of the distribution 'kernel', and the rate of departure differed among the three experiments (Table 1). The results of the three experiments differed quantitatively, but were qualitatively the same. A likely reason for the higher rate of departure in Experiment 6, as compared to Experiments 1 and 2, is the lower aphid density in Experiment 6.
This experiment was conducted in field \#16 on the Animal Science Farm, and aphid densities in this field at the time of the experiment were a factor of 4 lower $(12.5 \pm 1.0$ aphids per five standard sweeps with a sweep net) than in field \#14, in which experiments 1 and 2 were conducted and where the aphid densities were, respectively, $10.8 \pm 2.3$ and $11.3 \pm 2.1$ aphids per single sweep.

\section{Effect of sugar sprays on residence time and aggregation of $C$. septempunctata}

The results of the "sugar" experiments come in two parts. The first part is the actual departure of the marked beetles from sugar sprayed and control plots. The second part is the aggregation of unmarked beetles into sugarsprayed plots, following the spraying of sugar (and the subsequent release of a large number of lady beetles).

In each of the three experiments, the density of marked beetles declined rapidly after release in both sugarsprayed and control plots, in accordance with the results of the "wagon wheel" experiments. After a few days, none of the released beetles remained in the plots (Fig. 3). Equation 4 was fitted to determine $\lambda$, the relative rate of departure from the plots. In each of the three experiments, the departure rate was marginally greater in the control plots than in the sugar-sprayed plots. Figure 4 illustrates this point by showing that the average residence times $(1 / \lambda)$ in sugar sprayed plots were $20-30 \%$ longer than in control plots in each of the three experiments. When the fitted values for $\lambda$ are compared, assuming normal distributions of the fitted parameter values, the significance (one-sided p) of the difference would be $0.11,0.04$, and 0.16 in the three experiments, respectively. Given the consistency of the difference over three experiments, the difference may be considered real (though small). More importantly, residence time was very short in each of the experiments, and the majority of the released beetles left the plots within twelve hours of release. This is true for both sugar-sprayed and control plots.

Unmarked beetles, occurring naturally in the fields, aggregated rapidly into the sugar sprayed plots (Fig. 5). This is apparent in Experiments 4 and 5, but not in Experiment 3, due to a difference in methods. In Experiment 3, the sugar had been applied in the days before the release (as part of a pilot study not reported here), and reapplied shortly before the release of marked beetles. Hence, the aggregation of unmarked beetles had already taken place when sampling started. Experiments 4 and 5 were conducted in plots that had not been used in experiments before. The first sample was taken immediately before the application of sugar; hence, the aggregation process in response to sugar application could be monitored in these experiments. Experiments 4 and 5 showed rapid aggregation of unmarked lady beetles into the plots, while Experiment 3 confirmed the end result of this

TABLE 1. Dispersal and departure parameters, estimated from the data of the spatial mark-release experiments.

\begin{tabular}{ccccc}
\hline Experiment & Diffusion coefficient $\mathrm{D}\left(\mathrm{m}^{2} \mathrm{~h}^{-1}\right)$ & Relative departure rate $\lambda\left(\mathrm{h}^{-1}\right)$ & Residence time $[1 / \lambda](\mathrm{h})$ & $\mathrm{R}^{2}$ \\
\hline 1 & 1.90 & 0.08 & 12.5 & 0.986 \\
2 & 0.54 & 0.14 & 7.14 & 0.998 \\
6 & 0.17 & 0.63 & 1.59 & 0.999 \\
\hline
\end{tabular}




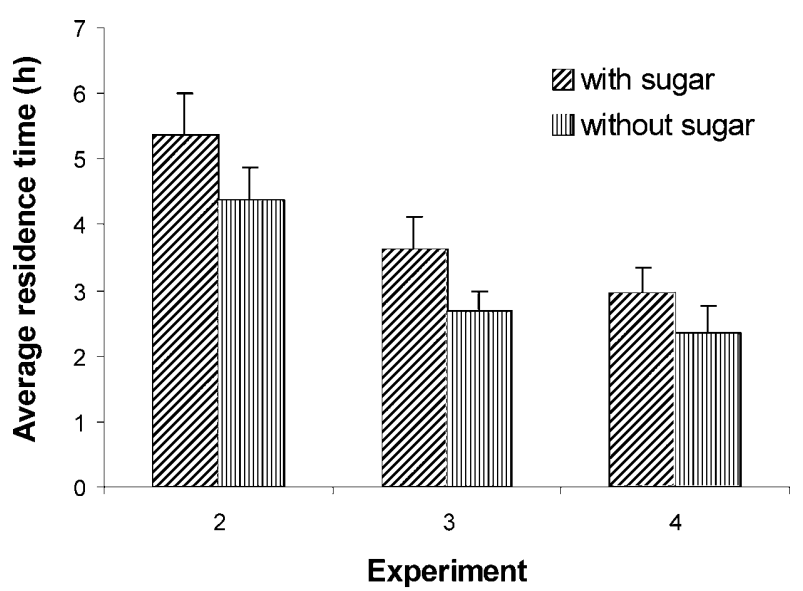

Fig. 4: Residence time $(1 / \lambda ; \mathrm{h}$.) of marked and released Coccinella septempuncatata in sugar sprayed and control plots, in three field experiments in alfalfa.

aggregation: a 10 to 20 -fold increase in lady beetle density, as shown in Fig. 6. The figure presents the ratio of densities of unmarked lady beetles in sugar-sprayed and control plots in each of the three experiments immediately before release (when the ratio is expected to be one in Experiments 4 and 5), and in the initial $13 \mathrm{~h}$ after release. The ratios show substantial (sampling) variability, but an overall pattern can still be identified: equilibrium in the aggregation process is reached four to six hours after the application of sugar. Hence, aggregation is a quick process, which reaches equilibrium in a matter of hours.

\section{Interpretation}

These results can be used to obtain an estimate of the relative departure rate of the lady beetles from sugar sprayed and control plots that is wholly based on observations on unmarked beetles. Such an estimate can be used as a check on the validity of the results obtained with marked beetles, which could potentially be affected by the disturbance of collecting, storing and marking, even though our direct observations in the field suggest that these individuals are quite representative in their behaviour. The estimate is arrived at by developing a basic model for immigration and emigration. Immigration is assumed to be an external "force" ( $I$; beetles per 8 sweeps per $h$ ) that is not affected by beetle density at the immigration site (note, however, that it may be different between sugar-sprayed and control plots). Emigration is assumed proportional to the number of beetles present, and hence the rate of change in population density can be expressed as:

$$
\frac{d P}{d t}=I-\lambda P
$$

This model requires only the least of plausible assumptions. Starting from a beetle density of zero, aggregation follows a time course according to:

$$
P=\frac{1}{\lambda}(1-\exp [-\lambda t])
$$

The initial slope of such a time course is $I$, and the equilibrium density is given by $I / \lambda$. The ratio of the plateau and the initial slope therefore yields the average resi- dence time $(1 / \lambda)$ of the beetles. The data of Experiments 4 and 5 (Fig. 5) show that equilibrium is approximately 18 beetles per 8 sweeps, and that this equilibrium is reached in a time period of 4 to 6 hours. Hence, the immigration rate is in the order of 3 to 4.5 beetles per 8 sweeps per hour. Using these estimates, the average residence time (calculated from the ratio of equilibrium density to the rate of immigration) is estimated at approximately between 4 and 6 hours. This estimate is consistent with the results obtained with marked beetles (Fig. 4), thus confirming our assertion that the marked beetles showed biologically representative behaviour.
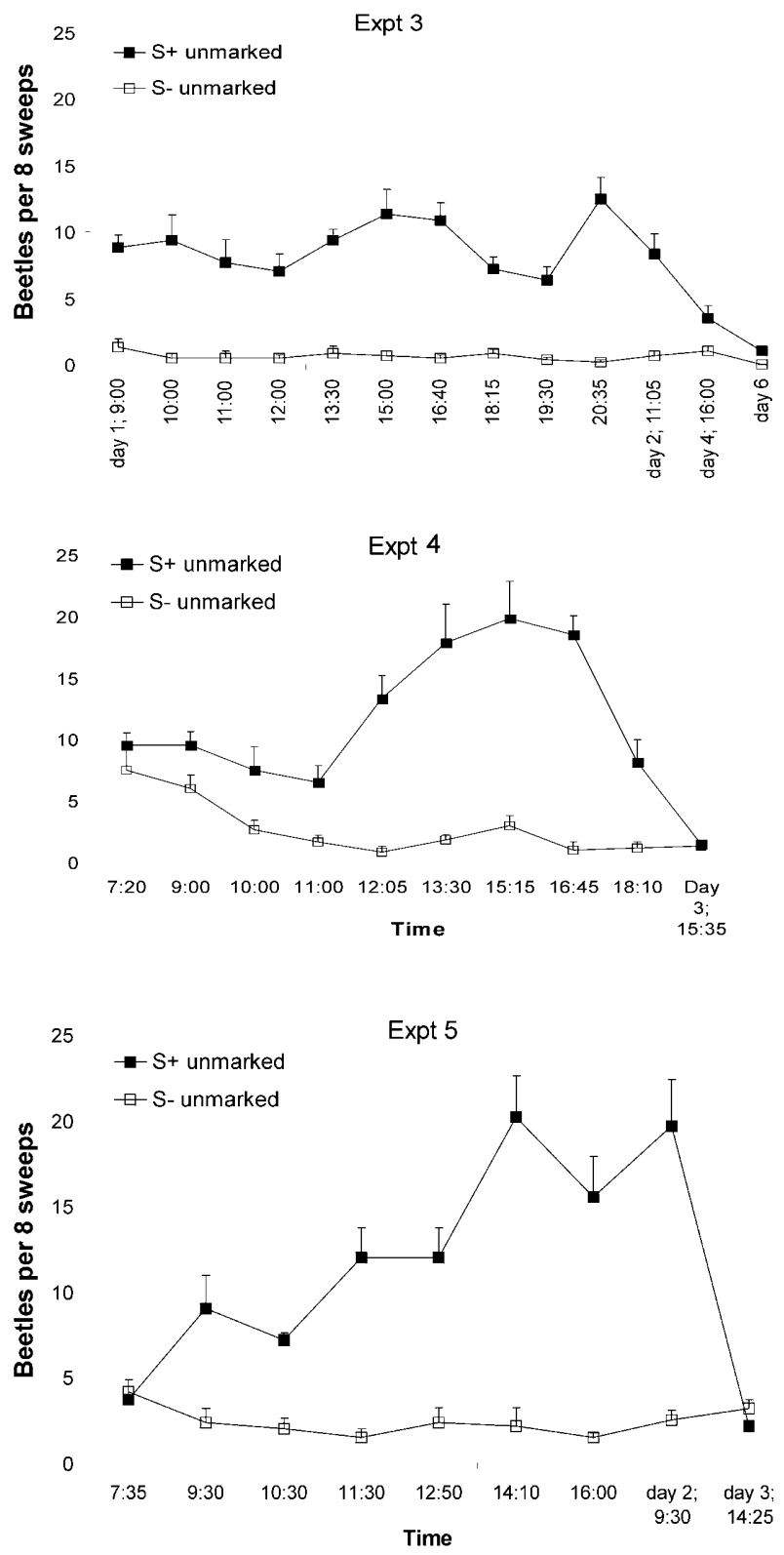

Fig. 5: Density of naturally occurring (unmarked) Coccinella septempunctata (expressed as lady beetles per 8 sweeps) in sugar sprayed and control alfalfa field plots in the course of time after release of marked beetles, in three field experiments in alfalfa. Sugar was sprayed immediately prior to the release of marked beetles. 


\section{DISCUSSION}

The field experiments described in this paper show that residence times of the lady beetle $C$. septempunctata in large plots of alfalfa $(0.36 \mathrm{ha})$ were in the order of hours under the conditions of the study. The majority of the population of beetles in such an area is therefore replenished daily with new individuals. This rapid turnover of the predator population in large areas probably reflects that few pea aphids, the primary prey of C. septempunctata in Utah alfalfa, were present during our experiments. In general, the tendency of predators such as lady beetles to stay in a resource patch (e.g. a field) increases with increasing quality of the patch (e.g., Ives et al., 1993). Given that prey densities were low throughout our study fields, it is likely that lady beetles not only quickly left the large study plots, but also rapidly emigrated from the fields in which these plots were placed. Hence, our results suggest that lady beetle populations are highly dynamic across the landscape, with substantial migration between fields, and localized dispersal within fields that is of limited importance, compared to between-field dispersal, under the conditions of this study. The tendency to emigrate when there are few prey is likely to result in predators aggregating at areas of high prey density (Evans \& Youssef, 1992; Hemptinne et al., 1992; Ives et al., 1993).

Rapid emigration of adult lady beetles also occurred from smaller study plots of alfalfa that we sprayed with sugar. This surprised us, as we had hypothesized that encounter with and consumption of sugar would lead to markedly longer residence in sugar-treated plots, as has been observed in the larvae of $C$. septempunctata (Carter \& Dixon, 1984). Especially surprising is the inference based on the combination of a marginally increased residence time (Fig. 4) and a 10 to 20 -fold increase in beetle density (Fig. 6) - that ladybeetle aggregation in sugarsprayed plots must have resulted primarily from increased

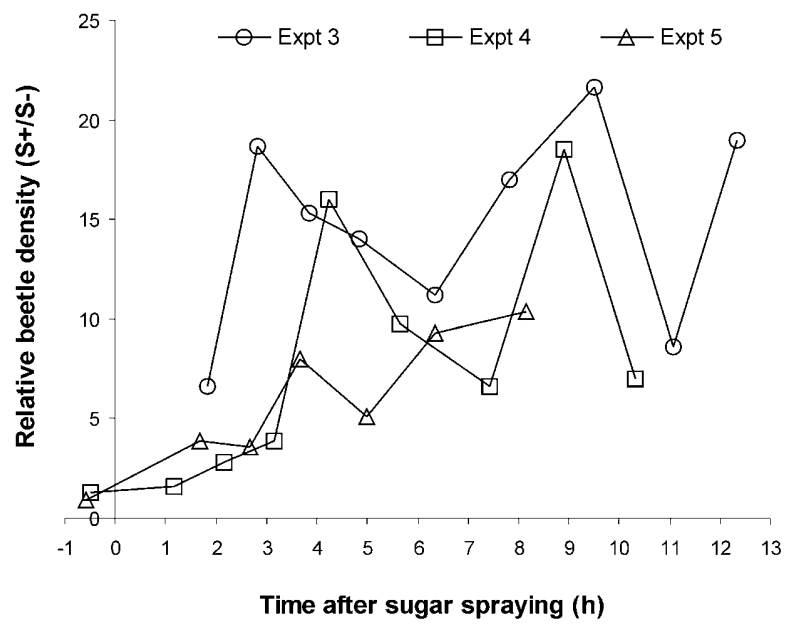

Fig. 6: Ratio of densities of Coccinella septempunctata in sugar sprayed and control alfalfa field plots in the course of time after spraying sugar, in three field experiments. In the course of 4-6 hours after sugar spraying, the density of ladybeetles in the sugar sprayed plots became 10-20 times as high as in the control plots. beetle immigration rather than decreased emigration. Because sugar is not volatile, we are led to hypothesize that early arriving lady beetles in sugar-treated plots release odours that attract additional lady beetles (early arriving beetles may benefit by attracting potential mates to a resource-rich area). To test this hypothesis we conducted Y-tube olfactometer studies (not reported here). In one of these studies we found positive responses of $C$. septempunctata to odour emanating from sugar sprayed alfalfa harbouring conspecific lady beetles. These measurements do not elucidate the source of the odour. It can not be ruled out that the spraying of sugar induces alfalfa plants to release volatiles that attract carnivores, as has for instance - been demonstrated for the secondary plant compound jasmonic acid in lima bean (Dicke et al., 1999; Thaler, 1999). There is independent evidence, however, that lady beetles ( $C$. septempunctata) are indeed using volatile compounds, pyrazines, produced by conspecifics, for orientation (Al Abassi et al., 1998). Indeed, it would be hard to understand how lady beetles manage to form overwintering aggregations without using chemical cues (Copp, 1983). Hodek \& Honěk (1996; p. 102) state: "Our anecdotal observations ... lead us to suspect that flying $C$. septempunctata adults do not land "blindly" on a field with still sparsely distributed aphid patches." We also observe that when one finds a lady beetle adult in an alfalfa field in early spring (when lady beetle and aphid densities are still very low), additional individuals are likely to be close by (E.W. Evans, pers. obs.). Hence, there is a body of evidence suggesting that lady beetles choose their whereabouts not at random, and that volatiles are involved in the selection of sites not only for overwintering, but also for foraging and/or mating. We plan further work to determine how this presumed attraction by volatiles actually works.

The results of our six field experiments show that individual lady beetles readily engage in long-distance dispersal when prey is not abundant, and that the availability of an alternative food source (sugar) leads to only modest increases in the tendency to linger in a local area when there is insufficient supply of the essential food for reproduction, aphids (Hodek \& Honěk, 1996; Evans, 2000). Orientation towards new foraging sites appears to be nonrandom and may well involve chemical cues.

ACKNOWLEDGEMENTS. The first author received a fellowship under the OECD Co-operative Research Programme: Biological Resource Management for Sustainable Agricultural Systems. Further material support was provided by USDA (NRI), and the Utah Agricultural Experiment Station. Andy Nelson, Chalk Simons, Julie Rieder, Anu Kalaskar, Rob Evans, Lauren Croft and Bouke, Sjoerd, Ulbe, Wiebe \& Wytse van der Werf gave expert field and lab. assistance, and Helen Jacob, Dave Drown, Jeremya Mohr, Jim Fry, Patty Rowan and Bill Brindley provided us with equipment and advise. The farm manager, D. Knudsen, adjusted his alfalfa cutting schedules to our research needs. Thank you all!

\section{REFERENCES}

Al Abassi S., Birkett M.A., Pettersson J., Pickett J.A. \& WoodCock C.M. 1998: Ladybird beetle odour identified and 
found to be responsible for attraction between adults. Cell. Mol. Life Sci. 54: 876-879.

BOMMARCO R. 1998: Reproduction and energy reserves of a predatory carabid beetle relative to agro-ecosystem complexity. Ecol. Appl. 8: 846-853.

Brewster C.C. \& Allen J.C. 1997: Spatiotemporal model for studying insect dynamics in large-scale cropping systems. Envir. Entomol. 26: 473-482.

Brewster C.C., Allen J.C., Schuster D.J. \& Stansly P.A 1997: Simulating the dynamics of Bemisia argentifolii (Homoptera: Aleyrodidae) in an organic cropping system with a spatiotemporal model. Envir. Entomol. 26: 603-161.

CARTER M.C. \& Dixon A.F.G. 1984: Honeydew: an arrestant stimulus for coccinellids. Ecol. Entomol. 9: 383-387.

CopP N.H. 1983: Temperature-dependent behaviours and cluster formation by aggregating ladybird beetles. Anim. Behav. 31: 24-430.

CORBETT A. 1998: The importance of movement in the response of natural enemies to habitat manipulation. In Pickett C.H. \& Bugg R.L. (eds): Enhancing Biological Control. Habitat Management to Promote Natural Enemies of Agricultural Pests. University of California Press, Berkeley, pp. 25-48.

DAVIDSON W.M. 1924: Observations and experiments on the dispersion of the convergent ladybeetle (Hippodamia convergens Guérin) in California. Trans. Am. Entomol. Soc. 50: 163-175.

Dicke M., Gols R., Ludeking D. \& Posthumus 1999: Jasmonic acid and herbivory differentially induce carnivore-attracting plant volatiles in Lima bean plants. J. Chem. Ecol. 25: 1907-1922.

Elliott N.C., Kieckhefer R.W., Lee J.H. \& French B.W. 1999 Influence of within-field and landscape factors on aphid predator populations in wheat. Landsc. Ecol. 14: 239-252.

Evars E.W. 2000: Egg production in response to combined alternative foods by the predator Coccinella transversalis. Entomol. Exp. Appl. 94: 141-147.

Evans E.W. 2000: Morphology of invasion: body size patterns associated with the establishment of Coccinella septempunctata in western North America. Eur. J. Entomol. 97: xx-xx.

Evans E.W. \& Richards D.R. 1997: Managing the dispersal of ladybird beetles (Coleoptera: Coccinellidae): use of artificial honeydew to manipulate spatial distributions. Entomophaga 42: $93-102$.

Evans E.W. \& SWallow J.G. 1993: Numerical responses of natural enemies to artificial honeydew in Utah alfalfa. Envir. Entomol. 22: 1392-1401.

Evans E.W. \& Youssef N.N. 1992: Numerical responses of aphid predators to varying prey density among Utah alfalfa fields. J. Kans. Entomol. Soc. 65: 30-38.

Ewert M.A. \& Chiang H.C. 1966. Dispersal of three species of Coccinellids in corn fields. Can. Entomol. 98: 999-1003.

Frazer B.D. 1988: Coccinellidae. In Minks A.K. \& Harrewijn P. (eds): Aphids; Their Biology, Natural Enemies and Control, Volume B. Elsevier Publ., Amsterdam, pp. 217-230.

HAGEN K.S. 1986: Ecosystem analysis: plant cultivars (HPR), entomophagous species and food supplements. In Boethel D.J. \& Eikenbary R.D. (eds): Interactions of Plant Resistance and Parasitoids and Predators of Insects. Wiley, New York, pp. 151-197.
Hemptinne J.-L., Dixon A.F.G., Coffin J. 1992: Attack strategy of ladybird beetles (Coccinellidae): factors shaping their numerical response. Oecologia 90: 238-245.

Hodek I. \& HonĚK A. 1996: Ecology of Coccinellidae. Kluwer Acad. Publ, Dordrecht, 464 pp.

Ives A.R., Kareiva P. \& Perry R. 1993: Response of a predator to variation in prey density at three hierarchical scales: lady beetles feeding on aphids. Ecology 74: 1929-1938.

IVES P.M. 1981: Estimation of coccinellid numbers and movement in the field. Can. Entomol. 113: 981-997.

Karerva P. 1987: Habitat fragmentation and the stability of predator-prey interactions. Nature (London) 326: 388-390.

Kareiva P. \& Odell G. 1987: Swarms of predators exhibit "preytaxis" if individual predators use area-restricted search. Am. Nat. 130: 233-270.

KieCKHEFER R.W. \& Olsen G.A. 1974: Dispersal of marked adult coccinellids from crops in South Dakota. J. Econ. Entomol. 67: 52-54

LANDIS D.A. \& HAAS M.J. 1992: Influence of landscape structure on abundance and within-field distribution of European corn borer (Lepidoptera: Pyralidae) larval parasitoids in Michigan. Envir. Entomol. 21: 409-416.

LANDIS D.A. \& VAN DER WERF W. 1997: Early season predation impacts the establishment of aphids and spread of beet yellows virus in sugar beet. Entomophaga 42: 499-516.

LOGAN J.D. 1997: Applied Mathematics, (second edition). John Wiley \& Sons, New York, 476 pp.

Logan J., White P., Bentz B. \& Powell J. 1997: Model analysis of the temporal evolution of spatial patterns in mountain pine beetle outbreaks. Theor. Pop. Biol. 53: 236-255.

MARINO P.C. \& LANDIS D.A. 1996: Effect of landscape structure on parasitoid diversity and parasitism in agroecosystems. Ecol. Appl. 6: 276-284.

Schiefelbein J.W. \& Chiang H.C. 1966: Effects of spray of sucrose solution in a corn field on the populations of predatory insects and their prey. Entomophaga 11: 333-339.

SteRn V.M., van Den Bosch R. \& LeIGH T.F. 1964: Strip cutting of alfalfa for Lygus bug control. Calif. Agric. 18: 4-6.

TSCHARNTKE T. \& KRUESS A. 1999: Habitat fragmentation and biological control. In Hawkins B.A. \& Cornell H.V. (eds): Theoretical Approaches to Biological Control. Cambridge University Press, Cambridge, pp. 190-205.

THALER J.S. 1999: Jasmonate-inducible plant defences cause increased parasitism of herbivores. Nature (London) 399: 686-688.

XIA J.Y. 1997: Biological Control of Cotton Aphid (Aphis gossypii Glover) in Cotton (inter) Cropping Systems in China; a Simulation Study. $\mathrm{PhD}$ Thesis Wageningen Agricultural University, Wageningen, $173 \mathrm{pp}$.

VAN DER WERF W. 1995: How do immigration rates affect predator/prey interactions in field crops? Predictions from simple models and an example involving the spread of aphidborne viruses in sugarbeet. In Toft S. \& Riedel W. (eds): Arthropod Natural Enemies in Arable Land. I Density Spatial Heterogeneity and Dispersal. Aarhus University Press. Acta Jutlandica 70: 295-312.

VAN EMDEN H.F. 1965: The role of uncultivated land in the biology of crop pests and beneficial insects. Scient. Hort. 17: 121-136.

Received January 6, 2000; accepted June 20, 2000 